\title{
LOW POWER STEAM TURBINE ENERGY EFFICIENCY AND LOSSES DURING THE DEVELOPED POWER VARIATION
}

\author{
Vedran MRZLJAK
}

\begin{abstract}
This paper investigates low power marine steam turbine during the variation in its developed power. The turbine is used for the Main Feedwater Pump (MFP) drive. Energy analysis of the Main Feedwater Pump Turbine (MFPT) is based on the measurements performed in nine different operating regimes. The measured operating parameters were steam pressure and temperature at the turbine inlet, steam pressure at the turbine outlet, and a water volume flow through MFP. Turbine energy power losses are most influenced by steam mass flow through the turbine and by steam specific enthalpy at the turbine outlet. An increase in turbine developed power causes a continuous increase in turbine energy efficiency. Analyzed turbine is balanced as most of the other steam system components - maximum energy efficiency will be obtained at the highest load, on which the majority of turbine and system operation can be expected during exploitation.
\end{abstract}

Keywords: energy efficiency; energy power losses; power variation; low power steam turbine

\section{INTRODUCTION}

Unlike the majority of marine transport in which diesel engine propulsion is dominant, steam propulsion systems are still used in the most of LNG carriers due to several important facts [1]. One of the most important reasons for steam propulsion system usage on LNG carriers is that the steam generators are capable of burning the entire amount of BOG (Boil-Off Gas) which occurs in LNG tanks. Each steam propulsion system consists of a large amount of components necessary for safe and reliable operation $[2,3]$.

In such a steam propulsion system, the main high pressure feed water pump is an important element - it returns water from the deaerator to steam generator and increases its pressure (usually through one or more high-pressure feed water heaters [4]). In most of the steam propulsion systems, the main high pressure feed water pump is traditionally driven by the low power steam turbine. In this paper, the Main Feedwater Pump Turbine (MFPT) is analyzed from the aspect of energy efficiency and energy power losses during the variation in turbine developed power. The measurements of MFPT steam operating parameters along with water volume flow through the Main Feedwater Pump (MFP), which are necessary for turbine numerical analysis, were made on a conventional LNG carrier during exploitation for a number of MFPT loads. The main characteristics and specifications of the LNG carrier in which the steam propulsion system is mounted and MFPT analyzed are presented in Table 1.

MFPT is a low power steam turbine, which consists of a single Curtis stage. Steam turbines with Curtis and other stages along with their complete analysis can be found in [5] and [6]. Many details of the classic and specific designs of marine steam turbines and their auxiliary systems are presented in [7] and [8].

The main goal of the MFPT analysis was to present change in the steam turbine energy efficiency and energy power losses during the change in turbine developed power.
In each presented turbine operating point the turbine developed power was varied from the lowest value of $50 \mathrm{~kW}$ up to the maximum power of $570 \mathrm{~kW}$ in steps of $20 \mathrm{~kW}$. During the power variation, turbine energy efficiency and energy power losses were calculated. The results of the analysis were presented for three randomly selected turbine operating points, but the presented conclusions are valid also for all the other operating points. In each operating point steam turbine developed power variation allows detecting optimal turbine loads with the highest energy efficiency. Turbine energy efficiency and energy power losses were compared from the real exploitation with achieved optimal ones. MFPT load depends on current water mass flow through the high pressure feedwater pump; from the aspect of energy efficiency, it is optimal for this turbine to constantly operate at the highest load (at $570 \mathrm{~kW}$ ) in each observed operating point. Turbine energy power losses are not the lowest at the highest turbine load; the lowest energy power losses were obtained at $37 \%$ of maximal turbine power (at $210 \mathrm{~kW}$ ) in each observed operating point.

Table 1 Main characteristics and specifications of the LNG carrier

\begin{tabular}{|c|c|}
\hline Dead weight tonnage & $84.812 \mathrm{DWT}$ \\
\hline Overall length & $288 \mathrm{~m}$ \\
\hline Max breadth & $44 \mathrm{~m}$ \\
\hline Design draft & $9.3 \mathrm{~m}$ \\
\hline Steam generators & $2 \times$ Mitsubishi MB-4E-KS \\
\hline Propulsion turbine & Mitsubishi MS40-2 (max. power $29.420 \mathrm{~kW})$ \\
\hline Turbo-generators & Shinko RGA 92-2 (max. power 3.850 kW each) \\
\hline
\end{tabular}

\section{EQUATIONS FOR THE MFPT ENERGY ANALYSIS}

\subsection{General Equations for the Turbine Energy Analysis}

Energy analysis of any steam system component is defined by the first law of thermodynamics, which is related to the conservation of energy [9]. Mass and energy balance, Eq. (1) and Eq. (2), for a standard volume in steady state disregarding potential and kinetic energy can be expressed according to [10] and [11] as 
$\sum \dot{m}_{\mathrm{IN}}=\sum \dot{m}_{\mathrm{OUT}}$

$\dot{Q}-P=\sum \dot{m}_{\mathrm{OUT}} \cdot h_{\mathrm{OUT}}-\sum \dot{m}_{\mathrm{IN}} \cdot h_{\mathrm{IN}}$

Flow energy power for any fluid stream (in this analysis, steam stream through the turbine) can be calculated according to the [12] using Eq. (3)

$$
\dot{E}_{\mathrm{en}}=\dot{m} \cdot h
$$

Energy efficiency, Eq. (4), can usually be written as [13]

$\eta_{\mathrm{en}}=\frac{\text { Energy output }}{\text { Energy input }}$

with the remark that energy efficiency can take different forms depending on the type of the system (or the system component if the energy analysis is performed just for one component).

\subsection{MFPT Energy Efficiency and Energy Power Losses}

Main Feedwater Pump steam Turbine (MFPT) is directly connected to the Main Feedwater Pump (MFP) which is used for increasing the water pressure and returning it to the steam generators, as shown in Fig. 1. MFPT consists of a single Curtis stage, while the whole unit has the following specifications [14]:

- $\quad$ pump delivery height: $818 \mathrm{~m}$

- $\quad$ pump maximum capacity: $175 \mathrm{~m}^{3} / \mathrm{h}$

- steam turbine maximum power: $570 \mathrm{~kW}$.

In Fig. 1, steam mass flow through MFPT ( $\left.\dot{m}_{\mathrm{MFP}}\right)$ is presented together with steam specific enthalpy and steam specific entropy at the turbine inlet and outlet. An important and measured operating parameter of the main feedwater pump, which will be used in the calculation of MFPT developed power, is pump water volume flow $\left(\dot{V}_{\mathrm{MFP}}\right)$.

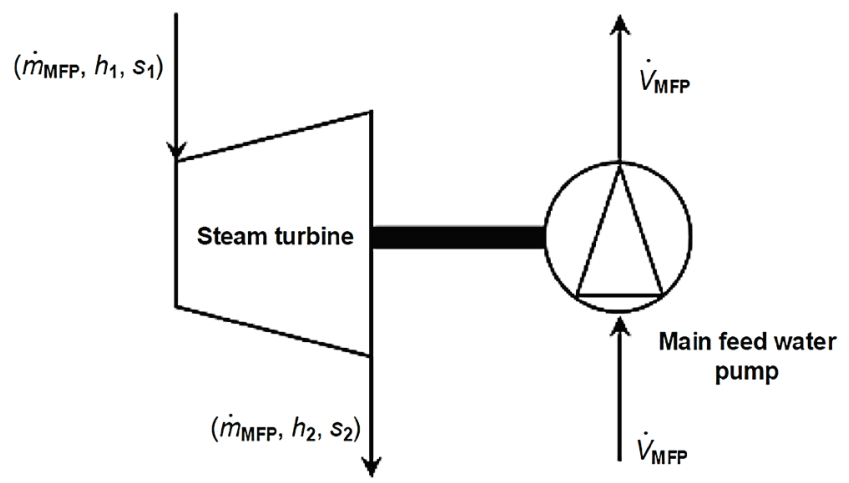

Figure 1 Change of main operating parameters through the analyzed turbine, which drives the high pressure pump

MFPT developed power was approximated from the pump water volume flow $\left(\dot{V}_{\text {MFP }}\right)$ by using third degree polynomial, Eq. (5), according to the producer specifications [14]. Main feed water pump water volume flow in relation to the MFPT developed power was calculated for medium water density $\rho_{\mathrm{fw}}=937.48 \mathrm{~kg} / \mathrm{m}^{3}$ at a water temperature of $T_{\mathrm{fw}}=$ $127^{\circ} \mathrm{C}$, according to the producer recommendations. MFPT developed power was calculated as follows:

$$
\begin{aligned}
P_{\mathrm{MFPT}}= & 1.786 \times 10^{-5} \cdot \dot{V}_{\mathrm{MFP}}^{3}-3.089 \times 10^{-3} \cdot \dot{V}_{\mathrm{MFP}}^{2}+ \\
& +2.002 \cdot \dot{V}_{\mathrm{MFP}}+189.48
\end{aligned}
$$

where $P_{\text {MFPT }}$ was obtained in $\mathrm{kW}$ when $\dot{V}_{\text {MFP }}$ in $\mathrm{m}^{3} / \mathrm{h}$ was placed in the Eq. (5).

Steam mass flow through MFPT was approximated with the turbine produced power $P_{\mathrm{MFPT}}$. Approximation was made according to the producer specifications [14], by using third degree polynomial, Eq. (6):

$$
\begin{aligned}
\dot{m}_{\mathrm{MFP}}= & -3 \times 10^{-5} \cdot P_{\mathrm{MFPT}}^{3}+3.133 \times 10^{-2} \cdot P_{\mathrm{MFPT}}^{2}- \\
& -4.397 \cdot P_{\mathrm{MFPT}}+2386.6
\end{aligned}
$$

where $\dot{m}_{\mathrm{MFP}}$ was obtained in $\mathrm{kg} / \mathrm{h}$ when $P_{\mathrm{MFPT}}$ in $\mathrm{kW}$ was placed in the Eq. (6).

During the measurements steam leakage on the MFPT was not observed, so the mass balance for the MFPT inlet and outlet, Eq. (7), is as follows:

$\dot{m}_{\mathrm{MFP}, 1}=\dot{m}_{\mathrm{MFP}, 2}=\dot{m}_{\mathrm{MFP}}$

According to Fig. 1 and Fig. 2, $h_{1}$ is steam specific enthalpy at the turbine inlet and $h_{2}$ is steam specific enthalpy at the turbine outlet after real (polytropic) expansion. Steam specific enthalpy at the turbine inlet $\left(h_{1}\right)$ as well as steam specific entropy at the turbine inlet $\left(s_{1}\right)$ were calculated from the measured steam pressure and temperature at the turbine inlet. Steam specific enthalpy at the turbine outlet $\left(h_{2}\right)$ was calculated from the MFPT developed power $P_{\mathrm{MFPT}}$ in $\mathrm{kW}$ and from steam mass flow through the turbine $\dot{m}_{\mathrm{MFP}}$ in $\mathrm{kg} / \mathrm{s}$ according to [15], using an Eq. (8):

$h_{2}=h_{1}-\frac{P_{\mathrm{MFPT}}}{\dot{m}_{\mathrm{MFP}}}$

The steam specific entropy at the turbine outlet $\left(s_{2}\right)$ was calculated from steam specific enthalpy at the turbine outlet $\left(h_{2}\right)$ and measured pressure at the turbine outlet $\left(p_{2}\right)$.

Specific enthalpy after isentropic steam expansion $\left(h_{2 \mathrm{~s}}\right)$ was calculated from the measured steam pressure at the turbine outlet $\left(p_{2}\right)$ and from the known steam specific entropy at the turbine inlet $\left(s_{1}\right)$. Ideal isentropic expansion assumes no change in steam specific entropy $\left(s_{1}=s_{2 \mathrm{~S}}\right)$, as presented in Fig. 2. The complete turbine energy analysis presented in this 
paper is based on comparison of real (polytropic) steam expansion and ideal (isentropic) steam expansion.

Steam specific enthalpy at the turbine inlet $\left(h_{1}\right)$, steam specific enthalpy at the end of turbine isentropic expansion $\left(h_{2 \mathrm{~S}}\right)$, and both steam specific entropies (at the turbine inlet $s_{1}$ and outlet $s_{2}$ ) were calculated by using NIST REFPROP 8.0 software [16].

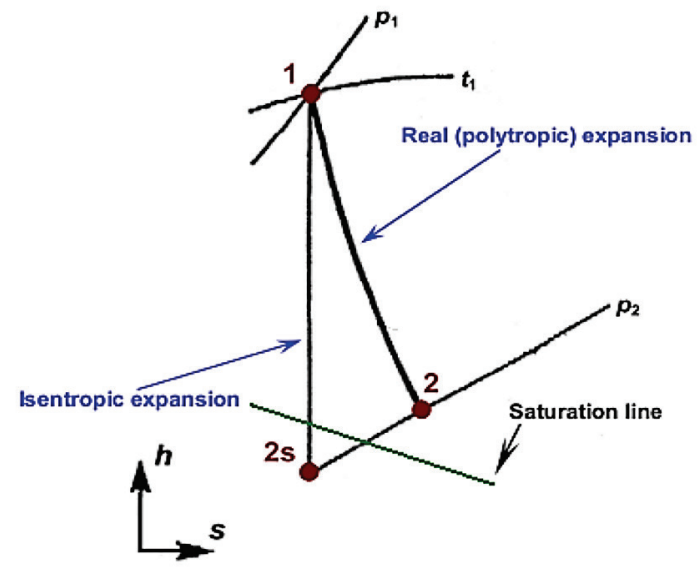

Figure 2 Turbine real (polytropic) and ideal (isentropic) expansion

MFPT energy power losses, Eq. (9), in each turbine operating point can be calculated according to Fig. 2 as:

$\dot{E}_{\mathrm{MFPT}, \mathrm{en}, \mathrm{PL}}=\dot{m}_{\mathrm{MFP}} \cdot h_{2}-\dot{m}_{\mathrm{MFP}} \cdot h_{2 \mathrm{~S}}=\dot{m}_{\mathrm{MFP}} \cdot\left(h_{2}-h_{2 \mathrm{~S}}\right)$

Energy efficiency of MFPT can be calculated according to [17] by using the Eq. (10):

$\eta_{\mathrm{MFPT}, \mathrm{en}}=\frac{\left(h_{1}-h_{2}\right)}{\left(h_{1}-h_{2 \mathrm{~S}}\right)}$

\subsection{The Principle of the MFPT Developed Power Variation}

MFPT developed power can be calculated according to Fig. 2 using an Eq. (11):

$P_{\mathrm{MFPT}}=\dot{m}_{\mathrm{MFP}} \cdot\left(h_{1}-h_{2}\right)$

Three different methods can be used for the MFPT power change (if the same steam inlet pressure and temperature and the same steam outlet pressure are assumed in every turbine operating point):

1) Change in steam mass flow through the MFPT;

2) Change in the value of steam specific enthalpy at the steam turbine outlet $\left(h_{2}\right)$;

3) Combination of methods 1 and 2.

In this paper, the combined method (method 3) was selected for each operating point to present the change of MFPT energy efficiency and energy power losses.

Turbine developed power was varied from $50 \mathrm{~kW}$ up to a maximum of $570 \mathrm{~kW}$ in steps of $20 \mathrm{~kW}$. Power change requires a change in steam mass flow through the turbine, so the corresponding steam mass flow for any turbine power was calculated by using the Eq. (6). At each operating point, steam pressure and temperature at the turbine inlet and steam pressure at the turbine outlet remain identical to the measured data. Steam enthalpy at the turbine outlet $\left(h_{2}\right)$ was calculated for each turbine power and mass flow by using Eq. (8). Change in steam enthalpy at the turbine outlet $\left(h_{2}\right)$ along with the change of steam mass flow cause the change of MFPT energy efficiency and energy power losses according to Eq. (9) and Eq. (10).

\section{MEASURING EQUIPMENT AND MEASUREMENT RESULTS OF THE ANALYZED MFPT}

Measurement results were obtained from the existing measuring equipment mounted on the MFPT inlet and outlet and on the main feedwater pump inlet. The list of the measuring equipment used is presented in Tab. 2 .

Table 2 Measuring equipment for the analyzed turbine and main feedwater pump

\begin{tabular}{|c|c|}
\hline $\begin{array}{c}\text { Steam temperature } \\
\text { (MFPT inlet) }\end{array}$ & $\begin{array}{c}\text { Greisinger GTF 601-Pt100 - Immersion } \\
\text { probe [18] }\end{array}$ \\
\hline $\begin{array}{c}\text { Steam pressure } \\
\text { (MFPT inlet) }\end{array}$ & Yamatake JTG980A - Pressure \\
\hline Steam pressure & Transmitter [19] \\
(MFPT outlet) & Yamatake JTG940A - Pressure \\
\hline $\begin{array}{c}\text { Feedwater volume flow } \\
\text { (pump inlet) }\end{array}$ & Transmitter [19] \\
\hline
\end{tabular}

Measurement results of the required operating parameters at MFPT inlet and outlet along with water volume flow at the main feed water pump inlet are presented in Table 3. Operating points in Tab. 3 present an LNG carrier steam system load ( 1 is the lowest observed system load, 9 is the highest observed system load). MFPT load is directly proportional to the steam system load; higher steam system load denotes a higher MFPT load and vice versa.

Table 3 Turbine and main feedwater pump measurement results in various

\begin{tabular}{|c|c|c|c|c|}
\hline O.P.* & $\begin{array}{c}\text { MFP water } \\
\text { volume flow } \\
\left(\mathrm{m}^{3} / \mathrm{h}\right)\end{array}$ & $\begin{array}{c}\text { Steam } \\
\text { temperature at } \\
\text { the MFPT inlet } \\
\left({ }^{\circ} \mathrm{C}\right)\end{array}$ & $\begin{array}{c}\text { Steam } \\
\text { pressure at } \\
\text { the MFPT } \\
\text { inlet }(\mathrm{MPa})\end{array}$ & $\begin{array}{c}\text { Steam pressure } \\
\text { at the MFPT } \\
\text { outlet }(\mathrm{MPa})\end{array}$ \\
\hline 1 & 69.71 & 497 & 5.980 & 0.272 \\
\hline 2 & 76.64 & 502 & 6.074 & 0.266 \\
\hline 3 & 82.90 & 510 & 6.067 & 0.251 \\
\hline 4 & 87.29 & 511 & 6.078 & 0.237 \\
\hline 5 & 94.22 & 513 & 6.020 & 0.239 \\
\hline 6 & 100.52 & 512 & 6.010 & 0.256 \\
\hline 7 & 106.01 & 510 & 5.874 & 0.235 \\
\hline 8 & 117.04 & 500 & 5.795 & 0.250 \\
\hline 9 & 118.26 & 500 & 5.900 & 0.246 \\
\hline O.P. $=$ Operating Point & \multicolumn{5}{l}{}
\end{tabular}

\section{ENERGY EFFICIENCY AND ENERGY POWER LOSSES DURING MFPT DEVELOPED POWER VARIATION}

The change in MFPT energy efficiency and energy power losses during the turbine developed power variation was performed in each operating point from Tab. 3 . Complete analysis gives a conclusion that increase or decrease in turbine developed power resulted with the same 
trends in each operating point. The only differences which occurred between any two operating points in Tab. 3 are the values of turbine energy efficiencies and losses.

Therefore, it is not necessary to present the change in MFPT energy efficiency and losses for each observed operating point, but it is important to show the change for at least several turbine loads. Loads from Tab. 3 selected for deeper discussion in this paper are the lowest turbine load (Operating point 1), one of the middle turbine loads (Operating point 5), and the highest observed turbine load (Operating point 9).

\subsection{MFPT Developed Power Variation for Operating Point 1}

Change in energy efficiency for MFPT in operating point 1 (Tab. 3), during the developed power variation is shown in Fig. 3. Increase in turbine developed power causes an increase in energy efficiency from the lowest to the highest observed turbine load. Continuous increase in MFPT energy efficiency, according to Eq. (10), is caused by a continuous decrease in steam specific enthalpy at the turbine outlet $\left(h_{2}\right)$ during power variation from $50 \mathrm{~kW}$ to $570 \mathrm{~kW}$. At the lowest observed turbine power of $50 \mathrm{~kW}$ at this operating point, energy efficiency amounts to only $10.63 \%$, while maximum turbine energy efficiency is obtained at the highest turbine developed power of $570 \mathrm{~kW}$ and amounts to $60.30 \%$.

Turbine energy efficiency in each operating point, as well as in operating point 1, is calculated by using Eq. (10). For each operating point, energy efficiency change is affected only by the change in steam specific enthalpy after real polytropic expansion $\left(h_{2}\right)$ which is calculated according to Eq. (8). Change of turbine developed power causes changes in steam mass flow through the turbine which is calculated by using Eq. (6), where the turbine power is a known and steam mass flow is an unknown variable. Values of steam specific enthalpy after real polytropic expansion $\left(h_{2}\right)$ decrease through entire observed turbine power range because the intensity of increase in turbine power is higher in comparison with an increase in steam mass flow through the turbine.

MFPT load is directly proportional to the ship steam system load. In operating point 1 , MFPT energy efficiency during LNG carrier exploitation amounts to only $47.74 \%$, which is $12.56 \%$ lower energy efficiency than the possible maximum one for this operating point.

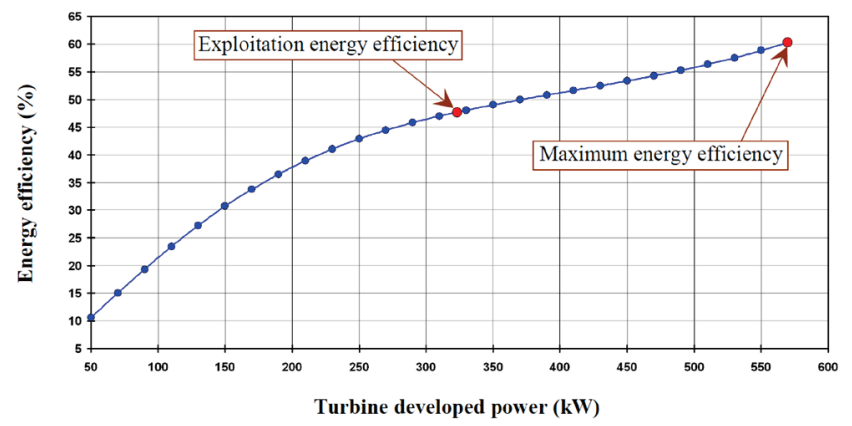

Figure 3 Energy efficiency change during MFPT developed power variation for operating point 1
Change in MFPT energy efficiency also shows that this turbine is balanced as most of the other steam system components - maximum energy efficiency will be obtained at the highest turbine (steam system) load on which the majority of LNG carrier operation can be expected.

MFPT energy power loss is calculated by using Eq. (9) for each observed operating point. Turbine energy power loss is most influenced by steam mass flow through the turbine and by steam specific enthalpy after real polytropic expansion $\left(h_{2}\right)$. For any developed turbine power in each operating point, steam specific enthalpy after isentropic steam expansion $\left(h_{2 \mathrm{~S}}\right)$ remains the same because of constant steam pressure and temperature at the turbine inlet and steam pressure at the turbine outlet.

During MFPT power variation from $50 \mathrm{~kW}$ up to 570 $\mathrm{kW}$, steam mass flow through the turbine continuously increases from $2241.33 \mathrm{~kg} / \mathrm{h}$ (at $50 \mathrm{~kW}$ ) to $4502.45 \mathrm{~kg} / \mathrm{h}$ (at $570 \mathrm{~kW}$ ), while in the same turbine load range steam specific enthalpy after real polytropic expansion $\left(h_{2}\right)$ continuously decreases from $3335.89 \mathrm{~kJ} / \mathrm{kg}$ (at $50 \mathrm{~kW}$ ) to $2960.45 \mathrm{~kJ} / \mathrm{kg}$ (at $570 \mathrm{~kW}$ ). Intensity of change in these two variables defines the change of MFPT energy power loss during the power variation for each observed turbine operating point, as well as for operating point 1 .

Fig. 4 presents the change in MFPT energy power loss during the turbine power variation. At the lowest turbine power of $50 \mathrm{~kW}$, energy power loss is the highest and amounts to $420.55 \mathrm{~kW}$. Between turbine power of $50 \mathrm{~kW}$ and $210 \mathrm{~kW}$, energy power loss decreases, so in this turbine operating range a decrease in steam specific enthalpy after polytropic expansion $\left(h_{2}\right)$ has a stronger influence on energy power loss than an increase in steam mass flow through the turbine.

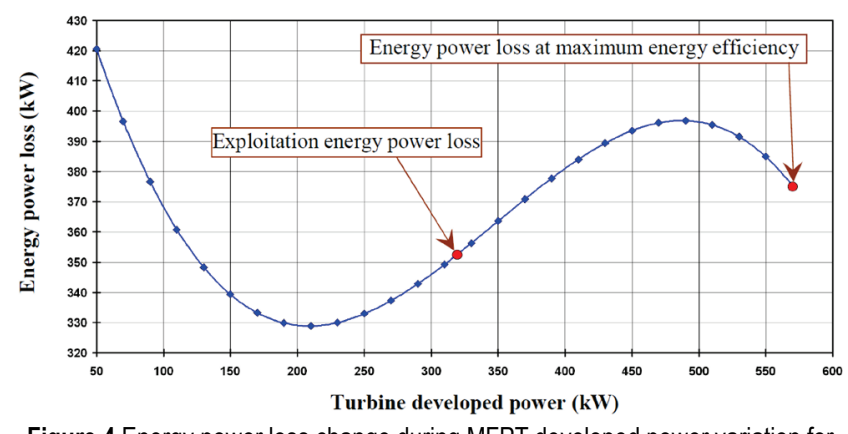

Figure 4 Energy power loss change during MFPT developed power variation for operating point 1

In the MFPT power range from $210 \mathrm{~kW}$ to $490 \mathrm{~kW}$ energy power loss increases, so in this turbine operating range an increase in steam mass flow through the turbine has a stronger influence on energy power loss than a decrease in steam specific enthalpy after polytropic expansion $\left(h_{2}\right)$.

From turbine power of $490 \mathrm{~kW}$ up to the maximum turbine power of $570 \mathrm{~kW}$, the influence of steam mass flow through the turbine and steam specific enthalpy after polytropic expansion $\left(h_{2}\right)$ on energy power loss is the same as in turbine power range from $50 \mathrm{~kW}$ to $210 \mathrm{~kW}$. As a result, in this power range turbine energy power loss decreases. 
During the LNG carrier exploitation in operating point 1, the MFPT energy power loss amounts to $350.35 \mathrm{~kW}$, while at turbine maximum energy efficiency in this operating point (at the highest turbine developed power of $570 \mathrm{~kW}$ ) turbine energy power loss amounts to $375.27 \mathrm{~kW}$.

The MFPT energy power loss is not proportional to turbine energy efficiency, or to the LNG carrier steam system load. From the viewpoint of MFPT energy power loss only, it will be optimal that the turbine operates at partial load, lower than in exploitation (the lowest energy power loss in this operating point is obtained at turbine developed power of $210 \mathrm{~kW}$ and amounts to $328.91 \mathrm{~kW}$ ). On the other side, at turbine energy power loss minimum in this operating point turbine energy efficiency achieved will be lower than in exploitation and will amount to only $38.97 \%$, Fig. 3 .

Conclusion valid for all MFPT operating points is that it should be decided which element should have priority during turbine operation - minimum energy power loss or maximum energy efficiency, because both goals cannot be obtained at the same time for this low power turbine. The majority of LNG carrier operation will be at the maximum steam system load, so the MFPT producer's goal surely was to achieve maximum energy efficiency.

\subsection{MFPT Developed Power Variation for Operating Point 5}

MFPT energy efficiency change in operating point 5 (Tab. 3), during the developed power variation is presented in Fig. 5. As in previously observed operating point 1 , an increase in turbine developed power causes a continuous increase in energy efficiency until the maximum value at maximum turbine power of $570 \mathrm{~kW}$.

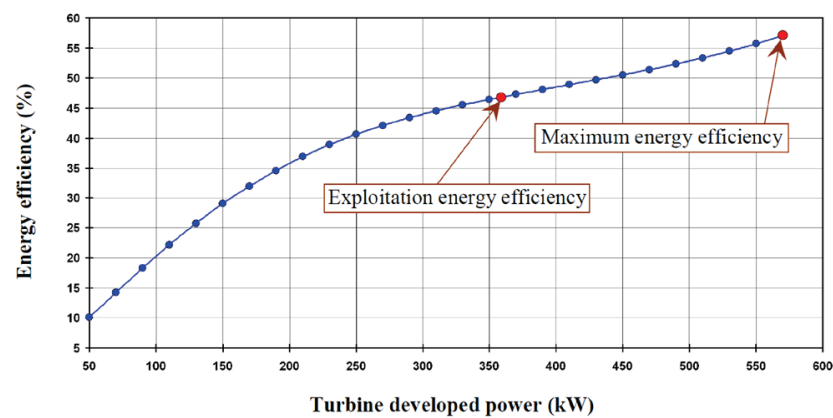

Figure 5 Energy efficiency change during MFPT developed power variation for operating point 5

In operating point 5 , maximum energy efficiency is obtained as before at the highest turbine developed power and amounts to $57.12 \%$. During the LNG carrier exploitation turbine energy efficiency amounts to only $47.41 \%$, which is $9.71 \%$ lower energy efficiency then the maximum obtained one at this operating point. At the lowest observed turbine load of $50 \mathrm{~kW}$, the lowest energy efficiency, which amounts to $10.07 \%$, can be seen in Fig. 5 .

The reasons for such MFPT energy efficiency change in operating point 5 are identical as in operating point 1 described before.
Turbine energy power loss, in operating point 5 as in operating point 1 , is most influenced by steam mass flow through the turbine and by steam specific enthalpy after real polytropic expansion $\left(h_{2}\right)$. Intensity of change in these two variables, described for turbine operating point 1 , is identical for operating point 5 and for all the other MFPT operating points. Additionally, for a turbine operating point 5 , the change in energy power loss trend of increase or decrease occurred at turbine developed power of $210 \mathrm{~kW}$ and $490 \mathrm{~kW}$.

Fig. 6 presents the change in MFPT energy power loss during the turbine power variation for operating point 5 . At the lowest turbine power of $50 \mathrm{~kW}$, energy power loss is the highest and amounts to $446.76 \mathrm{~kW}$. During the LNG carrier exploitation in operating point 5, the MFPT energy power loss amounts to $405.97 \mathrm{~kW}$, while at turbine maximum energy efficiency in this operating point (at the highest turbine developed power of $570 \mathrm{~kW}$ ) turbine energy power loss amounts to $427.92 \mathrm{~kW}$.

The lowest energy power loss in operating point 5 is obtained at turbine developed power of $210 \mathrm{~kW}$ and amounts to $358.85 \mathrm{~kW}$, Fig. 6, but at the lowest energy power loss turbine energy efficiency amounts to only $36.91 \%$, which is lower energy efficiency than in exploitation, Fig. 5.

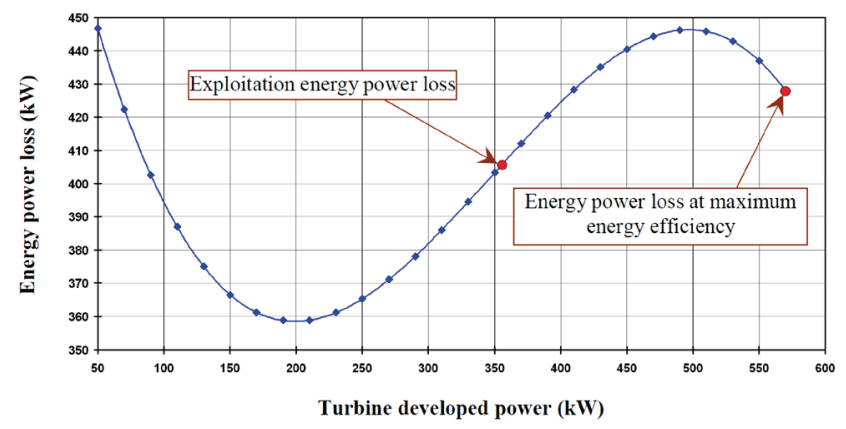

Figure 6 Energy power loss change during MFPT developed power variation for operating point 5

\subsection{MFPT Developed Power Variation for Operating Point 9}

The same trends and conclusions obtained from MFPT operating points 1 and 5 are also valid for operating point 9 (Tab. 3). In operating point 9, maximum turbine energy efficiency amounts to $58.78 \%$ and as before, is obtained at the highest turbine developed power of $570 \mathrm{~kW}$. At the lowest turbine load $(50 \mathrm{~kW})$ in this operating point, energy efficiency amounts to $10.36 \%$, while during the LNG carrier exploitation MFPT energy efficiency amounts to $50.83 \%$. During exploitation, MFPT energy efficiency is lower for $7.95 \%$ than the maximum obtained one in operating point 9 , Fig. 7.

MFPT operating point 9 also confirmed the conclusion that energy power losses are most influenced by steam mass flow through the turbine and by steam specific enthalpy after polytropic expansion $\left(h_{2}\right)$, Fig. 8. Intensity of change in these two variables is the same as in two operating points described before. Again, also in this turbine operating point, the change in energy power loss trend of increase or decrease occurred at turbine developed power of $210 \mathrm{~kW}$ and $490 \mathrm{~kW}$. 


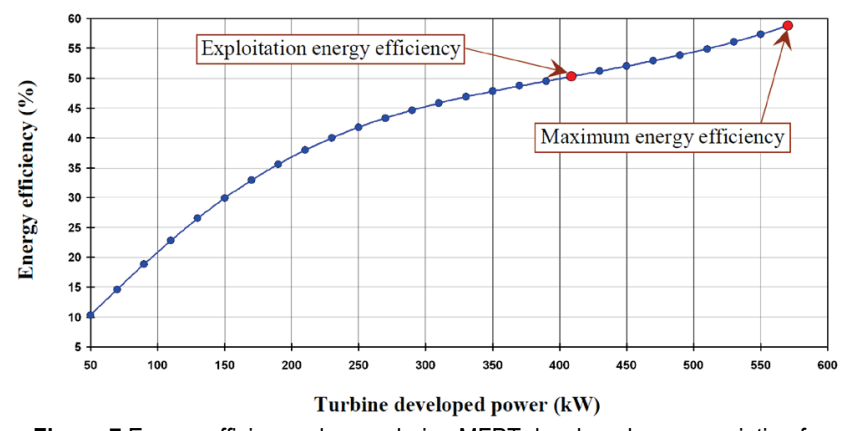

Figure 7 Energy efficiency change during MFPT developed power variation for operating point 9

At the lowest turbine power of $50 \mathrm{~kW}$, energy power loss is the highest and amounts to $432.69 \mathrm{~kW}$. During the LNG carrier exploitation in operating point 9 , the MFPT energy power loss amounts to $402.56 \mathrm{~kW}$, while at turbine maximum energy efficiency in this operating point (at the highest turbine developed power of $570 \mathrm{~kW}$ ) turbine energy power loss amounts to $399.65 \mathrm{~kW}$.

The lowest energy power loss in operating point 9 is obtained at turbine developed power of $210 \mathrm{~kW}$ and amounts to $342.81 \mathrm{~kW}$, Fig. 8, but at the lowest energy power loss turbine energy efficiency amounts to only $37.99 \%$, which is lower energy efficiency than in exploitation, Fig. 7.

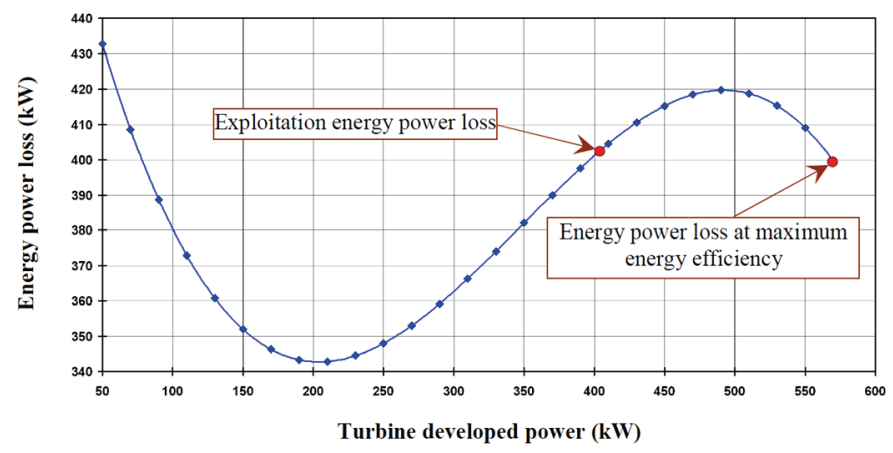

Figure 8 Energy power loss change during MFPT developed power variation for operating point 9

\section{CONCLUSION}

The paper presents numerical analysis of MFPT energy efficiency and energy power losses change during the variation in turbine developed power. The measurements were performed in nine different steam turbine operating points and numerical analysis has been presented in three randomly selected operating points. Nevertheless, the major conclusions are valid for the entire turbine operating range.

Increase in turbine developed power from $50 \mathrm{~kW}$ up to $570 \mathrm{~kW}$ in steps of $20 \mathrm{~kW}$ causes a continuous increase in turbine energy efficiency from the lowest to the highest obtained values. The continuous increase in MFPT energy efficiency is caused by a continuous decrease in steam specific enthalpy at the turbine outlet $\left(h_{2}\right)$ during power variation. The fact that the highest energy efficiencies will be obtained at the highest (maximum) turbine load is valid for all the observed turbine operating points. During turbine exploitation, energy efficiencies obtained are significantly lower than maximal ones in each operating point.

MFPT energy power losses are most influenced by steam mass flow through the turbine and by steam specific enthalpy after polytropic expansion $\left(h_{2}\right)$. Intensity of change in these two variables defines areas of turbine energy power loss increase and decrease. The change in energy power loss trend occurs at turbine developed power of $210 \mathrm{~kW}$ and $490 \mathrm{~kW}$. Minimum turbine energy power loss is detected at developed power of $210 \mathrm{~kW}$, while maximum turbine energy power loss is obtained at the lowest turbine load $(50 \mathrm{~kW})$, which is valid for the entire steam turbine operating range.

Analysis of MFPT resulted with the conclusion that this low power steam turbine is not designed to operate at the lowest energy power loss, but is designed to operate at maximum energy efficiency (obtained at turbine maximal loads), as the most of the other steam system components. The design goal of all the LNG carrier steam system components is to obtain highest efficiencies at the highest loads since the majority of LNG carrier operation can be expected on highest loads.

Further investigation of this turbine will be based on performing exergy and exergo-economic analysis. The goal will be to find operating regimes in which the MFPT operation is the most cost-effective while retaining acceptable efficiencies.

\section{ACKNOWLEDGMENT}

The author would like to extend his appreciation to the main ship-owner office for conceding measuring equipment and for all help during the exploitation measurements. This work was supported by the University of Rijeka (contract no. 13.09.1.1.05).

\section{NOMENCLATURE}

$\begin{array}{ll}\mathrm{fw} & \text { feedwater } \\ h & \text { specific enthalpy, } \mathrm{kJ} / \mathrm{kg} \\ \dot{m} & \text { mass flow, } \mathrm{kg} / \mathrm{s} \mathrm{or} \mathrm{kg} / \mathrm{h} \\ p & \text { pressure, } \mathrm{MPa} \\ s & \text { specific entropy, } \mathrm{kJ} / \mathrm{kg} \cdot \mathrm{K} \\ \mathrm{BOG} & \text { Boil-Off Gas } \\ \dot{E} & \text { stream flow power, } \mathrm{kJ} / \mathrm{s} \\ \mathrm{IN} & \text { inlet } \\ \mathrm{LNG} & \text { Liquefied Natural Gas } \\ \text { MFP } & \text { Main Feedwater Pump } \\ \mathrm{MFPT} & \text { Main Feedwater Pump Turbine } \\ \mathrm{OUT} & \text { outlet } \\ P & \text { power, } \mathrm{kJ} / \mathrm{s} \\ \mathrm{PL} & \text { power loss } \\ \dot{Q} & \text { heat transfer, } \mathrm{kJ} / \mathrm{s} \\ \mathrm{RE} & \text { real } \\ \mathrm{S} & \text { isentropic } \\ T & \text { temperature, }{ }^{\circ} \mathrm{C} \\ \dot{V} & \text { volume flow, } \mathrm{m}^{3} / \mathrm{h} \\ \rho & \text { density, } \mathrm{kg} / \mathrm{m}^{3} \\ \eta & \text { efficiency, }- \\ \end{array}$




\section{REFERENCES}

[1] Schinas, O. \& Butler, M. (2016). Feasibility and commercial considerations of LNG-fueled ships. Ocean Engineering, 122, 84-96. https://doi.org/10.1016/j.oceaneng.2016.04.031

[2] Fernández, I. A., Gómez, M. R., Gómez, J. R., \& Insua, A. A. B. (2017). Review of propulsion systems on LNG carriers. Renewable and Sustainable Energy Reviews, 67, 1395-1411. https://doi.org/10.1016/j.rser.2016.09.095

[3] Koroglu, T. \& Sogut, O. S. (2018). Conventional and Advanced Exergy Analyses of a Marine Steam Power Plant. Energy, 163, 392-403. https://doi.org/10.1016/j.energy.2018.08.119

[4] Mrzljak, V., Poljak, I., \& Medica-Viola, V. (2017). Thermodynamical analysis of high-pressure feed water heater in steam propulsion system during exploitation. Shipbuilding, 68(2), 45-61. https://doi.org/10.21278/brod68204

[5] Bloch, H. P. \& Singh, M. P. (2009). Steam turbines-Design, Applications and Re-rating, $2^{\text {nd }}$ edition. The McGraw-Hill Companies, Inc.

[6] Sarkar, D. K. (2015). Thermal Power Plant - Design and Operation. Elsevier Inc.

[7] Baldi, F., Ahlgren, F., Melino, F., Gabrielii, C., \& Andersson, K. (2016). Optimal load allocation of complex ship power plants. Energy Conversion and Management, 124, 344-356. https://doi.org/10.1016/j.enconman.2016.07.009

[8] Haglind, F. (2011). Variable geometry gas turbines for improving the part-load performance of marine combined cycles - Combined cycle performance. Applied Thermal Engineering, 31, 467-476. https://doi.org/10.1016/j.applthermaleng.2010.09.029

[9] Kaushik, S. C., Siva Reddy, V., \& Tyagi, S. K. (2011). Energy and exergy analyses of thermal power plants: A review. Renewable and Sustainable Energy Reviews, 15, 1857-1872. https://doi.org/10.1016/j.rser.2010.12.007

[10] Hafdhi, F., Khir, T., Ben Yahyia, A., \& Ben Brahim, A. (2015). Energetic and exergetic analysis of a steam turbine power plant in an existing phosphoric acid factory. Energy Conversion and Management, 106, 1230-1241. https://doi.org/10.1016/j.enconman.2015.10.044

[11] Tan, H., Zhao, Q., Sun, N., \& Li, Y. (2016). Enhancement of energy performance in a boil-off gas re-liquefaction system of LNG carriers using ejectors. Energy Conversion and Management, 126, 875-888. https://doi.org/10.1016/j.enconman.2016.08.031

[12] Mrzljak, V., Poljak, I., \& Mrakovčić, T. (2017). Energy and exergy analysis of the turbo-generators and steam turbine for the main feed water pump drive on LNG carrier. Energy Conversion and Management, 140, 307-323. https://doi.org/10.1016/j.enconman.2017.03.007

[13] Mrzljak, V., Poljak, I., \& Medica-Viola, V. (2017). Dual fuel consumption and efficiency of marine steam generators for the propulsion of LNG carrier. Applied Thermal Engineering, 119, 331-346. https://doi.org/10.1016/j.applthermaleng.2017.03.078

[14] Final drawing for Main Feed Pump \& Turbine (2006). Shinko Ind. Ltd., Hiroshima, Japan, ship documentation.

[15] Ahmadi, G., Toghraie, D., Azimian, A., \& Akbari, O. A. (2017). Evaluation of synchronous execution of full repowering and solar assisting in a $200 \mathrm{MW}$ steam power plant, a case study. Applied Thermal Engineering, 112, 111-123. https://doi.org/10.1016/j.applthermaleng.2016.10.083

[16] Lemmon, E. W., Huber, M. L., \& McLinden, M. O. (2007). NIST reference fluid thermodynamic and transport propertiesREFPROP version 8.0. User's guide, Colorado.
[17] Kanoglu, M., Çengel, Y. A., \& Dincer, I. (2012). Efficiency Evaluation of Energy Systems. Springer Briefs in Energy, Springer. https://10.1007/978-1-4614-2242-6

[18] https://www.greisinger.de (Accessed: 10.12.2017)

[19] http://www.industriascontrolpro.com (Accessed: 12.12.2017)

[20] https://portal.endress.com (Accessed: 15.12.2017)

\author{
Author's contacts: \\ Vedran MRZLJAK, PhD, Assistant Professor \\ Faculty of Engineering, University of Rijeka \\ Vukovarska 58, 51000 Rijeka, Croatia \\ Tel. +38551651551 \\ E-mail: vedran.mrzljak@riteh.hr
}

